Revista Internacional Educon | ISSN 2675-672

Volume 2, n. 1, e21021004, jan./abr. 2021

bttps://doi.org/10.47764/e21021004

\title{
O Novo Ensino Médio: a disputa em torno de um velho projeto formativo
}

The New High School: the dispute over an old educational project

La Nueva Enseñanza Media: la disputa sobre un antiguo proyecto formativo

FERNANDA RIBEIRO DE SOUZA ${ }^{1}$

${ }^{1}$ Universidade Estadual do Oeste do Paraná. Instituto Federal do Paraná

RESUMO: Este artigo apresenta uma análise a respeito do processo de disputas que se configura em torno do projeto formativo do Novo Ensino Médio. Desenvolvido por meio de pesquisa bibliográfica e análise documental, retoma as perspectivas formativas expressas pelos documentos que configuraram as propostas de formação para o Ensino Médio a partir da década de 1990. Aborda, sobretudo, os princípios presentes na Reforma do Ensino Médio, instituída pela Lei no 13.415/2017, na nova Base Nacional Comum Curricular e nas Diretrizes Curriculares Nacionais para o Ensino Médio, aprovadas em 2018. Constatouse que a proposta do Novo Ensino Médio é marcada pelo retorno à centralidade curricular com base em competências e está submissa aos processos de reestruturação do capital, marcados pela retomada radical do neoliberalismo, assemelhando-se ao movimento ocorrido nos anos de 1990. Retoma, portanto, um velho projeto formativo, acentuando o caráter dualista da formação proposta para o Ensino Médio.

ENSINO MÉDIO. POLÍTICAS CURRICULARES. REFORMA DO ENSINO MÉDIO.

\begin{abstract}
This article presents an analysis of the dispute process that is configured around the New High School educational project. Developed through bibliographic research and document analysis, retake the formative perspectives expressed by the documents that shaped the training proposals for high school from the 90's. Addresses, mainly, the principles present in the High School Reform, instituted by law number 13.415/2017, in de High School Common Curricular Base, in the Nacional Curriculum Guidelines for High School, approved in 2018. It was found that the proposal of the New High School is marked by the return to the centrality of the curriculum based on competences and it is subject to the processes of capital restructuring, marked by the radical resumption of neoliberalism, resembling the movement that occurred in the 90's. Therefore, it resumes an old formative project, emphasizing the dualistic character of the formation proposed for High School.
\end{abstract} CURRICULUM POLICIES. HIGH SCHOOL REFORM. HIGH SCHOOL.

A autora cede à Revista Internacional Educon os direitos de primeira publicação do presente artigo. Aplicam-se os termos de uma licença Creative Commons Atribuição 4.0 Internacional (CC BY 4.0), que permite o uso irrestrito, a distribuição e a reprodução em qualquer meio desde que a publicaşão original seja corretamente citada. 
RESUMO: Este artículo presenta un análisis del proceso de disputa que se configura en torno al proyecto de formación del Nueva Enseñanza Media. Desarrollado mediante la investigación bibliográfica y el análisis documental, retoma las perspectivas formativas expresadas por los documentos que configuraron las propuestas de formación para el Enseñanza Media de los años noventa. Aborda, sobre todo, los principios presentes en la Reforma de la Enseñanza Media, instituida por la Ley n 13.415/2017, en la nueva Base Curricular Comun Nacional y en las Directrices del Curriculo Nacional para el Enseñanza Media, aprobados en 2018. Se constató que la propuesta del Nueva Enseñanza Media está marcada por el retorno a la centralidad curricular basada en competencias y está sujeta a los procesos de reestructuración del capital, marcados por la reanudación radical del neoliberalismo, asemejándose al movimiento ocurrido en la década de noventa. Por tanto, retoma un antiguo proyecto formativo, enfatizando el carácter dualista de la formación propuesta para a Enseñanza Media.

\section{ENSEÑNANZA MEDIA. REFORMA DE LA ENSEÑANZA MEDIA. POLÍTICAS CURRICULARES.}

\section{Introdução}

As políticas educacionais têm sido alvo de constantes ajustes no sentido de adequar os processos educativos, a formação para o trabalho e a conformação da subjetividade dos sujeitos às necessidades que emergem do contexto social e produtivo.

Manfredi (2002) destaca que as relações entre trabalho, escolaridade e profissionalização resultam de uma complexa rede de determinações, mediações e tensões entre as diferentes esferas da sociedade: econômica, social, política e cultural. Assim, as políticas educacionais são fruto de um complexo movimento histórico de construção/reconstrução, determinado por fatores de ordem econômico-social e político-cultural, que configuram o contexto em que atuam os diferentes protagonistas sociais e seus interesses.

Nesse devir, as discussões em torno do currículo têm suscitado intensas disputas a respeito da configuração do projeto formativo almejado para a formação básica dos sujeitos, tendo em vista a correlação de forças que se expressa no seio das contradições do sistema capitalista, a partir da relação trabalho/capital.

Este artigo apresenta um esforço de análise em torno dos elementos prescritivos que configuram a atual Reforma do Ensino Médio. Busca compreender o contexto de disputa que permeia a construção da proposta do Novo Ensino Médio, no sentido de restabelecer/fortalecer um projeto formativo de cunho pragmático e neoliberal ${ }^{1}$.

Partindo do pressuposto de que o estudo de políticas e reformas educacionais é indissociável da compreensão dos movimentos de reestruturação e manutenção do capital em um âmbito mais abrangente e de seus reflexos na organização e nas funções assumidas pelo Estado, propomos uma análise fundamentada em uma perspectiva teórico-metodológica materialista, histórica e dialética, buscando captar de forma crítica o movimento histórico que as constituem.

Nessa perspectiva, partimos da compreensão da realidade social considerada enquanto produto da atividade humana, compondo uma totalidade, síntese de múltiplas determinações, contradições e mediações. Nesse sentido, a compreensão do fenômeno pesquisado implica apreender essa totalidade de forma concreta, partindo de sua particularidade e desvelando as determinações que a constituem.

O materialismo histórico dialético permite uma análise crítica das relações sociais capitalistas, na medida em que possibilita desvelar o modo como se produzem as relações de trabalho, de cultura e de

\footnotetext{
1 O neoliberalismo tem como características principais a intervenção mínima do Estado, a globalização da economia, o incremento acentuado das privatizações, a desregulamentação dos direitos do trabalho e aplicação intensiva de novas tecnologias. O discurso neoliberal atribui à intervenção do Estado todos os males sociais e econômicos, propondo, portanto, a redefinição do seu papel, o livre mercado e a livre iniciativa.
} 
formação, partindo da compreensão do homem como ser ativo na produção e transformação da realidade social.

O movimento metodológico que configura a pesquisa baseou-se na realização de análise documental, a fim de compreender a configuração prescritiva da política educacional em curso, abordando o marco legal que constitui a proposta de Reforma do Ensino Médio, sobretudo os seguintes documentos: a Lei no 13.415/2017 (Brasil, 2017), que institui o Novo Ensino Médio, a Base Nacional Comum Curricular do Ensino Médio (Brasil, 2018a) e as Diretrizes Curriculares Nacionais para o Ensino Médio, atualizadas em 2018 (Brasil, 2018b).

Em termos bibliográficos, dialogamos com autores da área das políticas públicas educacionais e curriculares, como: Silva (2018); Silva e Scheibe (2017); Oliveira (2015); Freitas (2018); Lopes (2019); Neves (2005; 2011); Ciavatta e Ramos (2012); dentre outros.

No seio das relações sociais capitalistas, marcadas por interesses antagônicos em torno da propriedade privada dos meios de produção, da divisão social de classes e da exploração de uma classe pela outra, o Estado atua como aparelho de hegemonia, buscando, por meio de políticas sociais, amenizar os efeitos de estruturas que produzem a desigualdade, garantindo o processo de reprodução dos mecanismos de exploração e acumulação do capital, sem firmar compromisso com a superação substancial dessas estruturas.

No processo de disputa pela hegemonia em torno do projeto formativo proposto pelo Ensino Médio a partir da Reforma imposta pela Lei no 13.415/2017, destaca-se neste estudo, o caráter de contrarreforma ${ }^{2}$ assumido pela proposta, ressaltando o protagonismo do setor empresarial na sua configuração, retomando perspectivas conservadoras e instrumentais e reduzindo o processo educacional a uma perspectiva unilateral, pragmática e rudimentar.

\section{As disputas em torno do Ensino Médio}

As políticas educacionais foram avançando progressivamente no sentido de inserir os adolescentes e jovens entre 14 e 17 anos na escolarização pública obrigatória, por meio da edição de textos legais. A Constituição Federal de 1988 (Brasil,1988) assegurou, em seu artigo 208, inciso II, a progressiva extensão da obrigatoriedade e gratuidade do Ensino Médio. Com a Lei de Diretrizes e Bases da Educação Nacional, Lei no 9.394/1996 (Brasil, 1996), o Ensino Médio passou a constituir a etapa final da Educação Básica, configurando-se enquanto direito subjetivo de todos os cidadãos brasileiros. Porém, somente em 2009, a Emenda Constitucional n ${ }^{\circ}$ 59/2009 (Brasil, 2009) instituiu a obrigatoriedade da universalização do Ensino Médio até 2016.

$\mathrm{Na}$ prática, entretanto, o acesso a essa etapa da escolarização básica permanece um desafio. Historicamente permeado pela ausência de uma identidade própria e caracterizado pela tensão e o dualismo entre a formação para o trabalho e a formação geral (Kuenzer, 2007), essa etapa é marcada por altos índices de evasão e fracasso escolar, além do baixo desempenho apresentado pelos estudantes nas avaliações de larga escala. O acesso e a garantia de permanência dos jovens no Ensino Médio ainda não foi universalizado, demandando um conjunto de ações e políticas adequadas para assegurar uma educação de qualidade.

${ }^{2}$ Em alguns momentos, o Estado burguês reformista adquire um caráter tão regressivo, que desenvolve o que Gramsci (2002) denomina como contrarreforma. Este processo caracteriza-se pela restauração e conservação da ordem social e política, diferindo da revolução passiva, que, embora mantenha as estruturas sociais vigentes, propõe pequenas mudanças e concessões, sendo, portanto, marcada pela revolução-restauração ou modernização. Para Gramsci (2002), a contrarreforma pauta-se no conservadorismo regressivo, na restauração do velho para manter a reprodução e ampliação do capital. Assim, processos de contrarreforma definem-se no plano discursivo como movimento reformador e progressista, a fim de garantir a legitimidade de suas estratégias, entretanto, representam cortes, restrições e supressão de direitos sociais conquistados. 
Diante desse quadro, o Ensino Médio tem sido alvo constante de reformas, sob o pretexto de ampliar o processo de universalização, melhorar os índices de desempenho apresentados e atender as pressões sociais por maior qualidade. Entretanto, esses objetivos articulam-se a um interesse maior: de adequar essa etapa de ensino às necessidades produtivas de reprodução e ampliação da acumulação capitalista.

De acordo com a Lei de Diretrizes e Bases da Educação Nacional no 9.394/1996, o Ensino Médio apresenta como finalidades:

I - a consolidação e o aprofundamento dos conhecimentos adquiridos no ensino fundamental, possibilitando o prosseguimento de estudos;

II - a preparação básica para o trabalho e a cidadania do educando, para continuar aprendendo, de modo a ser capaz de se adaptar com flexibilidade a novas condições de ocupação ou aperfeiçoamento posteriores;

III - o aprimoramento do educando como pessoa humana, incluindo a formação ética e o desenvolvimento da autonomia intelectual e do pensamento crítico;

IV - a compreensão dos fundamentos científico-tecnológicos dos processos produtivos, relacionando a teoria com a prática, no ensino de cada disciplina (Brasil, 1996).

Desse modo, a proposta de formação prevista para o Ensino Médio fundamenta-se em três eixos: a formação do cidadão, a preparação para o trabalho e a preparação para a continuação dos estudos. Pretende, no plano discursivo, promover a formação humana tanto no sentido intelectual, científico, ético, estético quanto no que se refere à capacitação para o trabalho.

Partindo dessas perpsectivas, diversas disputas permeiam a definição do projeto formativo do Ensino Médio. Libâneo; Oliveira e Toschi (2012) destacam que a oferta dessa etapa da formação comporta diferentes concepções: a propedêutica, que pretende capacitar os estudantes para o prosseguimento dos estudos no curso superior; a técnica, cujo intuito é preparar a mão de obra para o mercado de trabalho; e a humanística/progressista, que toma a formação em um sentido amplo, compreendendo a integração da dimensão propedêutica e da técnica, de forma integrada e dinâmica, para o pleno desenvolvimento dos sujeitos.

A correlação de forças em torno do projeto formativo do Ensino Médio tem se configurado, desde a década de 1980, entre, de um lado, os setores da sociedade que concebem a escola a partir de um viés de formação eficientista e imediatista e, de outro, setores sociais que almejam para os filhos dos trabalhadores uma formação integrada e politécnica, que não se limite à capacitar para o trabalho, mas que também lhes possibilite entender ampla e criticamente tanto a sociedade em que vivem quanto a forma pela qual se estrutura o trabalho que realizam, tendo em vista a construção de formas mais humanas e igualitárias de produzir e viver.

Apesar das disputas, nesse período, as reformas educacionais propostas alinharam-se hegemonicamente à perspectiva neoliberal, pragmática e eficientista. Como consequência, tiveram forte conotação empresarial, vinculando a reestruturação do sistema educacional às demandas de formação subjetiva e de treinamento para o setor produtivo e às orientações de Organismos Internacionais.

Essa concepção remonta à racionalidade que vem sendo implementada na gestão administrativa e governamental das últimas décadas, a partir do processo de reestruturação produtiva do capitalismo global, em função do esgotamento do regime de acumulação pautado no modelo taylorista e fordista ${ }^{3}$. Essa nova racionalidade marcou-se pelo aprofundamento do fenômeno de globalização e pela

${ }^{3}$ De acordo com Harvey (2016), a partir da década de 1970 ocorreu o esgotamento do modelo de organização do trabalho taylorista-fordista, baseado no rígido controle dos processos de trabalho, na separação entre supervisão e execução do trabalho, na produção em massa, dentre outras. Como consequência desse esgotamento, ocorreu a queda das taxas de lucro e entra em crise o modelo de Estado de Bem-Estar Social. Respondendo à crise estrutural do capital e do Estado, reorganizou-se o sistema ideológico e de produção do capital, a partir das estratégias neoliberais que amalgamam as novas relações de produção capitalistas. 
implementação das fórmulas neoliberais para a disseminação de um conjunto de orientações políticas e econômicas que transformaram as formas de organização do Estado e de desenvolvimento das políticas sociais (Harvey, 2016).

O processo de reestruturação global do capital exigiu a construção de uma nova sociabilidade que se estendia a todas as esferas da vida: moral, cultural, ética, intelectual, espiritual, etc. A condição de dependência com relação à economia mundial conduziu rapidamente os países da América Latina à execução da agenda globalizante neoliberal.

De acordo com Silva e Abreu (2008), o processo de globalização levou às privatizações e a reorganização dos serviços públicos, com o enxugamento da estrutura estatal e a ampliação da participação das empresas privadas. Instituiu-se progressivamente as bases para um novo modo de racionalização que submetia os serviços públicos à lógica de mercado, de forma a atender aos interesses do capital.

Neves (2005) destaca que no Brasil, a partir de 1990, o governo de Fernando Henrique Cardoso reestruturou o Estado, atribuindo a ele um caráter gerencialista, ao transferir a maioria das funções produtivas e de serviços para a iniciativa privada. Neste viés, as políticas sociais foram amplamente privatizadas, por meio de estratégias de descentralização, fragmentação e focalização, cabendo ao Estado um papel de intervenção e gerência.

Pautadas nas orientações e reformas propostas por organizações internacionais como a Organização das Nações Unidas para a Educação, a Ciência e a Cultura (UNESCO), o Fundo Monetário Internacional (FMI) e o Banco Mundial (BM) e pressionadas por fatores relacionados ao financiamento externo, as políticas sociais foram ajustadas às exigências, agendas e pautas do mercado.

De acordo com Oliveira (2015), o desenvolvimento de políticas adquiriu, no contexto de um Estado Mínimo, cada vez mais, um caráter compensatório e focal, valorizando o lugar do Estado como regulador e administrador. Como consequência da centralização do papel do Estado regulador e da mercantilização no campo educacional, ocorreu a necessária padronização de práticas e dos currículos no âmbito pedagógico, controlados por meio das avaliações em larga escala.

Desse modo, os processos educacionais tiveram seu foco transferido para os resultados, com a implantação de sistemas de avaliação para medir e acompanhar o cumprimento de metas por parte dos sistemas de ensino e docentes.

A incorporação de tecnologias de base microeletrônica e a gestão do trabalho, conforme o modelo toyotista ${ }^{4}$, impunham ao campo da formação para o trabalho uma série de características necessárias aos trabalhadores, como a flexibilidade, a capacidade de aprender permanentemente, de fazer usos mais complexos e diversificados da linguagem oral e escrita, dentre outras.

Esses ditames incidiram diretamente sobre o projeto de formação necessário para a produção do trabalhador apto a atuar no novo cenário configurado pelo capital global. De acordo com Azevedo (2004), no âmbito educacional, as reformas impactam as formas de gestão, organização, financiamento e regulação da função social das instituições de ensino, propalando um projeto pedagógico e curricular voltado para a formação de mão de obra para o trabalho e à consolidação da ideologia neoliberal, por meio da reprodução de valores, padrões culturais e morais, como a competição e o individualismo.

\footnotetext{
4 Criado no Japão em 1950, esse novo método de produzir em parte convive e em parte substitui a linha de montagem por uma forma de produção mais flexível. No toyotismo a produção é voltada e conduzida diretamente pela demanda, sendo, portanto, diversificada e com estoque mínimo. De acordo com Oliveira (2006), o toyotismo é caracterizado pelo melhor aproveitamento possível do tempo de produção. Nesse novo sistema, o trabalho sofre os impactos da desregulamentação, da informalização, precarização e intensificação, sendo mais polivalente e multifuncional. A organização flexível fundamenta-se no envolvimento e na expropriação do intelecto do trabalhador. Por isso exige dos trabalhadores não apenas a execução de variadas tarefas (polivalência e flexibilidade), mas também a participação na implementação de melhorias nos processos de trabalho, com vistas a minimizar custos e elevar a produtividade.
} 
Nesse devir, a formação geral ganhou centralidade, tendo como função primordial desenvolver as competências sociais necessárias à adaptação do trabalhador ao novo paradigma produtivo, pautado na flexibilidade, polivalência e ediciência.

Freitas (2018) destaca que, nesse contexto, o setor empresarial passou a protagonizar, de forma cada vez mais intensa, os debates em torno da oferta, do currículo e do financiamento da educação básica, buscando dar hegemonia a um processo de empresariamento da educação.

O processo de empresariamento da educação, pautado na lógica neoliberal, propõe a hegemonia de um projeto formativo voltado para a formação subjetiva e pragmática das classes populares a partir das necessidades do mercado, reproduzindo uma formação pobre e unilateral.

No âmbito das disputas em torno das políticas educacionais, os empresários pretendem, não apenas a participação e o poder de decisão, mas, também, a ampliação das possibilidades de acumulação de capital, por meio de estratégias de marketing, responsabilidade social, benefícios fiscais e de parcerias com o Estado (Zanatta, 2017).

Reiterando o processo de disputa em torno da hegemonia do projeto formativo do Ensino Médio, Silva (2018) ressalta que nas últimas décadas, essa etapa foi alvo de inúmeras reformas, configuradas a partir da elaboração de Parâmetros Curriculares Nacionais, duas diretrizes curriculares de abrangência nacional para o Ensino Médio, duas para a Educação Profissional Técnica de Nível Médio, dois Decretos para esta modalidade, uma alteração constitucional e um projeto de lei ${ }^{5}$.

Dentre esses documentos, constata-se divergências substantivas no que se refere à identidade e às finalidades assumidas para a etapa, ressaltando a correlação de forças que configura os projetos formativos pleiteados para o Ensino Médio.

As Diretrizes Curriculares Nacionais para o Ensino Médio elaboradas em 1998 (Brasil, 1998), logo após a aprovação da Lei de Diretrizes e Bases da Educação Nacional no 9.394/1996, visava adequar a etapa de formação do Ensino Médio às orientações e padrões disseminados pelos Organismos Internacionais em função do processo de reestruturação produtiva do capitalismo.

As finalidades do Ensino Médio foram contempladas nas Diretrizes Curriculares Nacionais (Brasil, 1998) com base no caráter de formação geral, que, deveria ser alinhado à preparação e compreensão dos processos de trabalho, por meio do conhecimento acerca das tecnologias próprias das transformações técnico-científicas.

Nessa direção, a preparação geral para o trabalho, conforme prevê o Artigo 35 da Lei de Diretrizes e Bases da Educação Nacional foi proposta por meio de um processo de formação básica. Com isso, o Ensino Médio assumiu uma perspectiva formativa restrita, com vistas ao desenvolvimento de competências para a vida social e produtiva.

Todavia, a democratização da escolaridade básica não vinculou-se a uma possibilidade de ampliação do acesso aos conhecimentos científicos e culturais pelos trabalhadores, dada a simplificação dos procedimentos de trabalho possibilitada pela tecnologia microeletrônica e digital molecular, mas sim à perspectiva de prepará-los e adequá-los para enfrentar a flexibilidade do trabalho produtivo, os processos de desregulamentação, precarização e o desemprego.

Deste modo, as políticas educacionais adotadas com base na lógica empresarial pautaram-se em uma perspectiva de democratização da formação geral, destinada à capacitação de uma grande massa de

5 Os Parâmetros Curriculares Nacionais para o Ensino Médio (PCNEM) (Brasil, 2000); a Resolução CNE/CEB n 03/1998, que define as Diretrizes Curriculares Nacionais para o Ensino Médio (Brasil, 1998), com base no Parecer no 15/1998; a Resolução no 4/1999, que trata das Diretrizes Curriculares Nacionais para a Educação Profissional (Brasil, 1999); a Resolução n 2/2012, que define as Diretrizes Curriculares Nacionais para o Ensino Médio (Brasil, 2012a), com base no Parecer no 05/2011; a Resolução no 06/2012, que Define Diretrizes Curriculares Nacionais para a Educação Profissional Técnica de Nível Médio (Brasil, 2012b); a Emenda Constitucional no 59/2009 (Brasil, 2009) que institui a obrigatoriedade escolar para a faixa etária de 15 a 17 anos; o Projeto de Lei n 6.840/2013 (Brasil, 2013). 
trabalhadores que assumiria postos de trabalho flexíveis e precários e uma formação com base técnica e tecnológica para um número limitado de postos de trabalho, mais complexos.

Com isso se procedeu a focalização educação geral na etapa do Ensino Médio e a formação profissional foi relegada à níveis posteriores ao Ensino Médio. Ainda em 1997, o Decreto no 2.208/19976 formalizou a separação entre a formação geral e a formação profissional e técnica.

Posteriormente, a elaboração dos Parâmetros Curriculares Nacionais (PCN) (Brasil, 2000) sintetizou a hegemonia dos interesses empresariais na definição do projeto formativo da Educação Básica. O intuito do documento era o de produzir uma padronização curricular no país, em todos os níveis da Educação Básica, conforme estabelecia o Artigo 26, da Lei de Diretrizes e Bases da Educação Nacional, com relação à elaboração de um currículo comum nacional.

Pretendia-se estabelecer um projeto formativo com base na filosofia do "aprender a aprender"”, centrando a Educação Básica em uma formação aligeirada, visando o desenvolvimento de competências e habilidades e a preparação, sobretudo subjetiva, dos indivíduos para as demandas do mercado de trabalho, em detrimento da formação de um sujeito crítico e potencialmente emancipado.

Nesse documento, o currículo do Ensino Médio foi organizado a partir de três grandes áreas: Linguagens, Códigos e suas Tecnologias; Ciências da Natureza, Matemática e suas Tecnologias; e Ciências Humanas e suas Tecnologias. A inclusão do termo "e suas Tecnologias" em cada área do conhecimento, que já havia sido introduzido nas Diretrizes Curriculares Nacionais para o Ensino Médio (Brasil, 1998), pretendia atender a finalidade de compreensão científico-tecnológica dos fundamentos da produção e de preparação para o trabalho, conforme prevê a Lei de Diretrizes e Bases da Educação Nacional (Brasil, 1996).

Silva (2018) ressalta que a justaposição do termo "e suas tecnologias" em cada área do conhecimento explicita uma concepção reducionista de tecnologia, entendida como técnica a ser aplicada. Nesse sentido, o conceito de tecnologia foi limitado à aplicação de determinado conhecimento, negando as relações sociais que constituem os processos de produção tecnológica, marcados, sobretudo, pelo âmbito econômico e produtivo.

Assim, a compreensão dos fundamentos científico-tecnológicos dos processos produtivos e a preparação para o trabalho e para a cidadania, propostas na LDB, tornaram-se restritas nas Diretrizes Curriculares Nacionais para o Ensino Médio e nos Parâmetros Curriculares Nacionais, ao aprendizado do emprego da tecnologia com base em atividades práticas, valorizando o caráter utilitário dos saberes, numa perspectiva limitada e pragmática, visando adequar a formação às mudanças nos processos de organização do trabalho e alinhando-se a uma concepção reducionista de formação humana.

\footnotetext{
${ }^{6}$ O Decreto Federal no 2.208/1997 regulamentou os artigos 39 e 42 da LDB e organizou a educação profissional em três níveis: o básico, destinado a qualificação, requalificação e reprofissionalização de trabalhadores, sem considerar prévia escolaridade; o técnico, destinado aos alunos matriculados ou egressos do ensino médio, como forma de profissionalização; e o tecnológico, destinado a cursos de nível superior, com duração reduzida, nas áreas tecnológicas. No que se refere à ao currículo, o Decreto no 2.208/1997 estabeleceu que a educação profissional de nível técnico teria organização curricular própria e independente do ensino médio, podendo ser oferecida de forma concomitante ou sequencial. Deste modo, a Educação Profissional passou a ser desenvolvida em paralelo ao ensino regular ou em modalidades de educação continuada, podendo ser realizada em escolas regulares, em instituições especializadas ou nos ambientes de trabalho (Brasil, 1997).

${ }^{7}$ Essa perspectiva, assim como a de formação com base em competências, teve influência do Relatório Jaques Delors (Delors, 1998), originado da Reunião Internacional sobre Educação para o Século XXI da UNESCO, que definiu as quatro grandes necessidades de aprendizagem ou os quatro pilares da educação: aprender a conhecer, aprender a fazer, aprender a conviver e aprender a ser, estabelecendo como a principal finalidade da educação contemporânea a formação de personalidades flexíveis para a adaptação à realidade social e produtiva instável que se instaurava.
} 
Essa lógica opõe-se à concepção de formação integrada e humanística, que tem como princípio a garantia da apreensão dos fundamentos científicos e tecnológicos da produção e da base técnica das respectivas profissões pelos sujeitos, numa perspectiva omnilateral ${ }^{8}$ de formação humana.

De acordo com Silva (2018), a formação com base em competências associa-se ao conceito de tecnologias, visando adequar os processos formativos às demandas postas pelas mudanças decorrentes do processo de reestruturação social e produtiva. Por essa razão, a pesquisadora destaca que tecnologias, competências e habilidades e adequação ao mundo do trabalho são categorias centrais nas proposições da reforma curricular dos anos 1990.

As mudanças no cenário político brasileiro com o primeiro governo do Partido dos Trabalhadores, em 2003ํㅜ acenderam os debates em torno das finalidades do Ensino Médio. Neste ano foi realizado o Seminário Nacional de Ensino Médio, em Brasília, organizado pela Secretaria de Ensino Médio e Tecnológico (SEMTEC). Nele foram enunciadas as ideias centrais que sustentariam as concepções conceituais, epistemológicas e metodológicas de um outro projeto formativo proposto para a etapa final da Educação Básica.

A Educação Profissional Técnica de Nível Médio (EPTNM) tornou-se objeto de atenção, sendo alterada pelo Decreto no 5.154/200410 , que trazia a possibilidade da oferta do Ensino Médio Integrado. A oferta da educação profissional integrada ao ensino médio assentava-se em uma perspectiva teórica que divergia das diretrizes curriculares nacionais traçadas na década de 1990.

As bases conceituais do Ensino Médio Integrado estruturam-se na perspectiva do trabalho como princípio educativo, no conceito de formação politécnica e no processo de organização curricular pautado na integração entre ciência, cultura, tecnologia e trabalho, retomando, portanto uma perspectiva de formação omnilateral.

De acordo com Ciavatta e Ramos (2012), com base no trabalho como princípio educativo, na pesquisa como princípio pedagógico, na indissociabilidade entre educação e prática social, a proposta das novas Diretrizes Curriculares Nacionais para o Enino Médio pautou-se na possibilidade de integração de conhecimentos gerais e técnico-profissionais, realizada na perspectiva da interdisciplinaridade e da contextualização, relacionando teoria e prática na compreensão das formas de produção, de trabalho e ciência e cultura.

8 Para Manacorda (1991), a omnilateralidade é a conquista do desenvolvimento total, completo, multilateral, de todos os sentidos e faculdades humanas, por meio da apropriação pelo homem da totalidade das forças produtivas. Esse tipo de formação exige um ensino tecnológico que integre teoria e prática, tomando o trabalho como princípio educativo e abordando três aspectos: a educação intelectual, a educação corporal e a educação tecnológica. A produção do homem omnilateral requer a superação da divisão do trabalho e a união do trabalho manual e intelectual, por meio da vivência social efetiva e pelo trabalho produtivo. Nesta perspectiva, a omnilateralidade exige a construção de uma nova sociedade, em que o trabalho, enquanto manifestação da consciência do homem, frente às suas necessidades e vontades, não seja estranhado, alienado, como se apresenta na sociedade capitalista.

9 Enquanto nos dois governos liberais de Fernando Henrique Cardoso foi realizado o desmonte das bases do capitalismo desenvolvimentista e definido um novo arcabouço jurídico para a execução das políticas neoliberais, o governo de Lula da Silva fez uso da estrutura econômica, jurídica e política montada para estabelecer uma nova relação entre Estado e sociedade civil, que viabilizou a implementação de políticas neoliberais privatistas e focalizadas no atendimento de demandas sociais, dando ao seu governo um caráter mais popular, embora os fundamentos dos seus projetos políticos sejam idênticos (Neves, 2011). Essa postura conciliou a correlação de forças entre posições neoliberais e desenvolvimentistas, que de acordo com Neves (2011) acabou por configurar um modo híbrido de desenvolvimento para no país, buscando associar crescimento econômico e redução das desigualdades sociais, por meio de um maior investimento em políticas sociais.

10 A publicação do Decreto no 5.154/2004 (Brasil, 2004) revogou o Decreto no 2.208/1997 e determinou que a Educação Profissional e Técnica de Nível Médio fosse desenvolvida em articulação com o Ensino Médio, na forma integrada. Trouxe avanços em relação ao marco normativo anterior, mantendo, entretanto, a possibilidade de oferta de formação profissional na modalidade concomitante e subsequente, corroborando com a continuidade do modelo formativo em curso no país. 
Essas orientações e concepções impactaram as propostas formativas do Ensino Médio como um todo. Porém, só em 2012 foram materializadas nas novas Diretrizes Curriculares Nacionais para o Ensino Médio (DCNEM), homologadas pela Resolução CNE/CEB nº 02/2012 (Brasil, 2012a) e elaboradas com base no Parecer CNE/CEB no 05/2011.

A redefinição das Diretrizes Curriculares Nacionais permitiu avanços no sentido da superação, ao menos no âmbito formal, do caráter estrita e pragmaticamente vinculado ao mercado de trabalho que caracterizava as diretrizes anteriores, potencializando as possibilidades de acesso aos conhecimentos historicamente produzidos com base nas relações entre o trabalho, a ciência, a cultura e a tecnologia.

Entretanto, logo após sua homologação, deflagrou-se um novo marco no cenário de disputas em torno do projeto formativo do Ensino Médio. Em 2013, foi criada uma Comissão Especial na Câmara dos Deputados, com o propósito de estabelecer mudanças na organização da última etapa da educação básica. Do trabalho dessa comissão resultou o Projeto de Lei no 6.840/2013 (Brasil, 2013), cuja elaboração contou com forte participação dos setores empresariais e a contestação de grupos e setores ligados às escolas e universidades.

Esse projeto, que já divergia substantivamente das Diretrizes aprovadas em 2012, foi arquivado com a edição da Medida Provisória no 746/2016, imposta pelo Presidente Interino Michel Temer sem diálogo e consulta aos diversos setores da sociedade, logo após o golpe que culminou com o impeachment da Presidente Dilma Rousseff ${ }^{11}$, como uma das medidas de recomposição da hegemonia burguesa, que de certa forma, conciliou alguns anseios populares no decorrer dos governos Petistas.

A Medida Provisória resultou na Lei no 13.415/2017, que alterou a Lei de Diretrizes e Bases da Educação no que diz respeito à organização curricular e também a Lei no 11.494/2007, que regulamenta o Fundo de Manutenção e Desenvolvimento da Educação Básica e de Valorização dos Profissionais da Educação (FUNDEB), propondo um Novo Ensino Médio com base no princípio de flexibilização. De acordo com Silva e Scheibe (2017), a elaboração da proposta apresentou contornos autoritários e contou com intenso protagonismo de setores empresariais, assumindo similaridades com as concepções e estratégias implementadas na reforma da década de 1990, conforme demonstraremos na próxima seção deste texto.

\section{O Novo Ensino Médio}

Sancionada pela Lei no 13.415, em fevereiro de 2017, a reforma do Ensino Médio propôs alterações na organização curricular do Ensino Médio, na forma de oferta, na organização pedagógica e no financiamento. Propôs a flexibilização do currículo, por meio da definição de uma formação geral, fundamentada na Base Nacional Comum Curricular, com foco principalmente na Língua Portuguesa e Matemática, limitada a 1800 horas, e por itinerários formativos, a serem definidos pelos sistemas de ensino, com ênfase nas seguintes áreas de conhecimento ou de atuação profissional: I - linguagens e suas tecnologias; II - matemática e suas tecnologias; III - ciências da natureza e suas tecnologias; IV - ciências humanas e sociais aplicadas; e V - formação técnica e profissional (Brasil, 2017).

Estabeleceu no inciso $2^{\circ}$ do artigo $3^{\circ}$ que as únicas disciplinas obrigatórias nos três anos serão a Língua Portuguesa, a Matemática e o Inglês, que, de acordo com Gonçalves (2017), indica um viés de preparação dos estudantes para a realização de provas de desempenho e melhoria dos indicadores

\footnotetext{
${ }^{11}$ Em 2016 a então Presidente da República, Dilma Rousseff sofreu um processo de impeachment orquestrado por meio de um golpe jurídico, parlamentar e midiático, que lhe tirou do poder e conduziu um grupo de extrema direita, conservador e radical neoliberal para o comando do país. A conjuntura instalada apontou para um retorno ainda mais vigoroso da lógica neoliberal no país. No campo das políticas educacionais, a contrarreforma atual focaliza de modo especial o Ensino Médio e a Educação Profissional Técnica de nível Médio, propondo modificações com foco principalmente no processo padronização das bases curriculares nacionais.
} 
nacionais de qualidade da educação, atrelando ao currículo um cunho preparatório, imediatista e pragmático.

Disciplinas como Sociologia, Filosfia, Educação Física e Arte são incluídas na parte de formação geral do currículo a partir do "estudo e práticas" de seus conteúdos, atribuindo a essas áreas do conhecimento um caráter secundário na formação básica do estudante.

A Reforma propôs ainda a oferta do Ensino Médio em tempo integral, prevendo a ampliação progressiva do tempo para 1400 horas anuais, sem, entretanto, sustentar-se em uma perspectiva de formação integral que considere os estudantes em suas múltiplas dimensões e sem garantir a ampliação do financiamento necessário à operacionalização da extensão do tempo escolar com qualidade estrutural e humana.

Contraditoriamente à possibilidade de ampliação do tempo de formação escolar, a reforma limitou as possibilidades formativas dos estudantes, ao restringir o tempo destinado à formação geral, propondo um currículo flexível, a especialização precoce e o caráter terminal do Ensino Médio a todos aqueles que cursarem um itinerário formativo técnico e profissional.

Assim, ao possibilitar diferentes percursos para o Ensino Médio e ao implementar a formação técnica e profissional na Educação Básica, em vez de prever a integração dos conhecimentos gerais e técnicos, a reforma limitou as possibilidades de formação básica dos estudantes, promovendo a fragmentação e o esfacelamento curricular, separando e hierarquizando ciências e humanidades, trabalho e linguagem, ciências humanas e sociais, retomando o caráter pragmático pautado no conceito de formação com bases no desenvolvimento de competências expressas nas políticas da década de 1990 .

Permitiu que as instituições estabeleçam parcerias para a oferta da educação profissional e técnica, intensificando as associações com o empresariado e permitindo a transferência de fundos públicos da Educação Básica para a iniciativa privada, articulando a oferta educacional com a lógica produtivista e mercadológica (Gonçalves, 2017).

Ao possibilitar a oferta de até $20 \%$ do Ensino Médio na modalidade à distância para a faixa etária de 15 a 17 anos e até 80\% no caso da educação de jovens e adultos, a Reforma foi novamente ao encontro dos interesses mercadológicos dos setores empresariais, que ampliam suas possibilidades de lucro e acumulação, transformando a educação e, sobretudo a oferta do itinerário formação técnica e profissional em uma mercadoria.

Agravando as condições de oferta da formação técnica, a reforma permitiu o itinerário formação técnica e profissional considere a possibilidade de concessão de certificados intermediários de qualificação para o trabalho, organizando a formação em etapas com terminalidade, permitindo múltiplas possibilidades de aproveitamento de estudos e experiências para a integralização curricular, sem maior regulamentação, fazendo com que o itinerário da seja concluído até mesmo sem ter sido cursado integralmente.

Estabeleceu o reconhecimento de notório saber a profissionais para "ministrar conteúdos nas escolas de ensino médio afins à sua formação ou experiência profissional, atestados por titulação específica ou prática de ensino em unidades educacionais da rede pública ou privada (Brasil, 2017)”, o que contribui para desqualificar o trabalho docente e depreciar sua identidade.

Ao compreender a educação profissional como um itinerário formativo, a ser opcionalmente cursado na etapa final do Ensino Médio pelos estudantes, a partir de uma perspectiva pragmática e puramente técnica, desarticulada da formação geral prevista na etapa, rompe-se com uma perspectiva de integração e de formação com base no trabalho como princípio educativo e nos eixos da ciência, da cultura e do trabalho, conforme previam as Diretrizes Curriculares Nacionais para o Ensino Médio (Brasil, 2012a) e para a Educação Profissional Técnica de Nível Médio (Brasil, 2012b).

Desse modo, na proposta do Novo Ensino Médio, a formação técnica e profissional integrada à Educação Básica defendida por educadores críticos como direito e condição para uma formação plena dos estudantes, volta a ser negada, convertendo-se em um itinerário à parte da formação geral comum, cuja oferta será facilitada e barateada. 
Ao mesmo tempo em que limita o caráter propedêutico do Ensino Médio, ao fragmentar as possibilidades formativas por meio dos itinerários formativos, relegando uma formação de maior qualidade às escolas destinadas a formação da elite (privadas), a reforma retoma o caráter de formação para o trabalho simples, impulsionado pelas demandas de qualificação dos jovens trabalhadores e pela facilidade de implementação desse itinerário formativo por meio de parcerias lucrativas para o setor privado.

Com isso, as finalidades do Ensino Médio, definidas pela LDB de 1996 como a consolidação e o aprofundamento dos conhecimentos, possibilitando o prosseguimento de estudos e a preparação básica para o trabalho e a cidadania do educando são oportunizadas aos jovens de acordo com sua posição de classe na divisão social do trabalho, retomando o caráter dual historicamente presente nessa etapa da educação, marcado pela dicotomia entre formação geral e formação para o trabalho.

\section{A Nova Base Nacional Comum Curricular e as Diretrizes Curriculares Nacionais para o Ensino Médio}

A partir da retomada histórica do processo de disputas em torno da configuração das políticas educacionais e do projeto formativo do Ensino Médio, procedemos a análise de dois documentos fundamentais no processo de sustentação do Novo Ensino Médio, a fim de identificar as similaridades e divergências com relação aos dispositivos elaborados nas décadas de 1990 e 2000.

A Reforma do Ensino Médio foi amparada na definição de uma Base Nacional Comum Curricular, cuja configuração tem sido objeto de críticas de pesquisadores da área do currículo e das políticas educacionais, como Silva (2018), Lopes (2019), dentre outras.

Lopes (2019) destaca que uma base curricular comum pressupõe a definição de determinados conteúdos ou conhecimentos como os únicos válidos, aos quais é atribuído o status de conhecimento essencial a ser ensinado e aprendido, impondo metas uniformes e projetos identitários fixos, trajetórias de vida preconcebidas, pressão para conter a tradução e impor uma leitura curricular padrão.

Silva (2018) problematiza que a padronização inerente à Base Nacional Comum Curricular desconsidera as desigualdades de condições de oferta que marcam as redes e instituições de ensino, contribuindo para ampliá-las, na medida em que aquelas instituições que não conseguirem adequar as práticas pedagógicas às prescrições da nova base curricular serão consideradas ineficientes, independente do contexto que acompanha o processo de desenvolvimento da política educacional no âmbito da escola.

Costa e Silva (2019) destaca problemas de legitimidade com relação ao processo de produção da BNCC, pois o documento não foi fruto de participação coletiva e de consulta a entidades especializadas, do mesmo modo como ocorreu com a Reforma do Ensino Médio.

Morello e Horn (2020) ressaltam que a Base Nacional Comum Curricular (BNCC) teve sua primeira versão publicada para consulta pública em 2015. O documento organizava os conteúdos por meio de objetivos de aprendizagem e desenvolvimento para todas as etapas da Educação Básica.Para o Ensino Fundamental e Médio, a proposta estava organizada por áreas do conhecimento, apresentando os objetivos de todos os componentes curriculares (disciplinas) que constituem o currículo da Educação Básica.

Em 2016, antes da publicação da Medida Provisória no 746/2016, foi divulgada uma segunda versão da BNCC para um novo processo de consulta pública. Esse documento manteve a organização por áreas do conhecimento apresentando componentes curriculares de cada uma, mas agrupava os objetivos de aprendizagem e desenvolvimento em unidades curriculares.

Após a publicação da Medida Provisória no 746/2016, e sua posterior transformação na Lei $n^{\circ}$ 13.415/2017, foi apresentada, em 2017, uma terceira versão do documento substantivamente diferente quanto à organização e às expressões utilizadas. 
A Base Nacional Comum Curricular do Ensino Médio foi aprovada somente em 2018 pelo Conselho Nacional de Educação, claramente adequada às modificações propostas pela Reforma do Ensino Médio.

Considerando que o processo de seleção e elaboração curricular é objeto de disputas e interesses, a correlação de forças em torno do texto curricular assumido pela nova Base Nacional Comum Curricular expressa interesses hegemônicos relacionados às estratégias de manutenção e ampliação dos mecanismos de acumulação capitalistas.

Neste sentido, destacamos que o processo de reelaboração do documento apresentou uma confluência com os interesses de mercado, confirmada pela presença de reformadores empresariais (representantes da Fundação Lemann, Todos pela Educação, Movimento pela Base, entre outros) como vozes protagonistas na reformulação do texto (Silva; Scheibe, 2017).

Na versão aprovada, o termo "objetivos de aprendizagem e desenvolvimento" foi alterado para "habilidades e competências" retomando grande parte dos princípios contidos nas Diretrizes Curriculares Nacionais para o Ensino Médio de 1998 (Brasil, 1998) e nos Parâmetros Curriculares Nacionais (PCN) (Brasil, 2000).

Uma breve análise do documento permite constatar que os descritores, os códigos alfanuméricos e sua extrema prescrição, alinham-se às estratégias de avaliação em larga escala, revelando uma configuração curricular balizada pela padronização e uniformização.

Enfatiza-se, nesse sentido, a adequação das propostas curriculares aos mecanismos de monitoramento e controle, instituídos, sobretudo, a partir da aplicação de avaliações em larga escala, que funcionam tanto para o controle quanto para a indução do currículo, num claro alinhamento à racionalidade neoliberal aplicada às políticas educacionais a partir da década de 1990, que tiveram prosseguimento nas décadas seguintes.

Lopes (2019) chama a atenção para o fato de que a BNCC para o Ensino Médio, em direção oposta ao que é feito pela BNCC do Ensino Fundamental, não indica habilidades a serem desenvolvidas por anos ou por disciplinas (com exceção de Língua Portuguesa e Matemática, que apresentam centralidade em relação às demais, com as habilidades e competências descritas detalhadamente), nem estabelece sequências ou simultaneidades, de forma a tornar o currículo ainda mais flexível.

Nesse sentido, difere até mesmo dos Parâmetros Curriculares Nacionais, que listavam competências por disciplinas, produzindo uma organização híbrida, conciliando a estrutura curricular por áreas do conhecimento com a perspectiva disciplinar. Assim, o aspecto regressivo assumido pela atual reforma é ainda mais contundente em comparação à reforma da década de 1990, em que manteve-se a especificidade de cada disciplina na composição das áreas do conhecimento e sua articulação ao desenvolvimento de competências, sem invisibilizar conteúdos da Sociologia, Filosofia, Arte e História.

A organização curricular por competências assume centralidade no documento da Nova Base Nacional Comum Curricular, reforçando o rastro instrumental e regressivo. A partir de um viés pragmático, a organização do currículo com base em competências reduz o conhecimento escolar à sua condição de aplicabilidade imediata, acarretando uma fragilização na formação dos estudantes por meio da perda de centralidade do conhecimento.

O termo competência é definido no documento como "a mobilização de conhecimentos (conceitos e procedimentos), habilidades (práticas, cognitivas e socioemocionais), atitudes e valores para resolver demandas complexas da vida cotidiana, do pleno exercício da cidadania e do mundo do trabalho" (Brasil, 2018a, p. 08).

Esse conceito reitera uma perspectiva economicista que pretende adequar o projeto formativo às necessidades impostas pelo sistema produtivo, primando por uma formação que assegure o desenvolvimento de competências gerais, articuladas à "construção de conhecimentos, no desenvolvimento de habilidades e na formação de atitudes e valores” (Brasil, 2018a, p. 09).

De acordo com Silva (2018), longe de representar uma inovação, trata-se da retomada do modelo que se tentou implementar no país ao final da década de 1990, conforme abordamos na seção anterior. 
Lopes (2019) problematiza que a organização de toda a proposta curricular com base em competências submete a educação ao registro instrumental de um saber-fazer, conferindo ao processo formativo um estreitamento curricular. Para a pesquisadora,

Com isso, a educação mais uma vez permanece reduzida ao ensino e o ensino, por sua vez, fica restrito ao atendimento de metas de aprendizagem vinculadas ao saber fazer e à resolução de problemas associados a demandas da vida cotidiana (como se tais demandas do que se supõe ser a vida cotidiana fossem as mesmas para todas e todos) (Lopes, 2019, p. 69).

Nessa concepção, o conhecimento historicamente elaborado, apropriado e transposto pela instituição escolar para fins didáticos perde sua dimensão histórica e social e limita-se a uma perspectiva pragmática e instrumental, como conhecimento pronto e socialmente visto como necessário/útil, a ser transmitido pela escola e adquirido pelos estudantes.

Do mesmo modo que a nova Base Nacional Comum Curricular, as Diretrizes Curriculares para o Ensino Médio, atualizadas pela Resolução CNE/CEB no 3/2018 (Brasil, 2018b), propõem o foco na aplicação dos conhecimentos originários das diferentes áreas na solução de problemas, conferindo pouca atenção à gênese econômica, política e social de tais problemas (Ferretti, 2018).

A aprovação desses regulamentos associa-se a outros dispositivos normativos que pretendem readequar e controlar o currículo do Ensino Médio. Esse conjunto de documentos define ações com relação à governança e ao regime de colaboração; exige que as redes reelaborem seus currículos; propõe a adequação dos livros e materiais didáticos, buscando atender as habilidades e competências impostas; propõe que a formação inicial e continuada de professores seja controlada por meio de ações de avaliação e monitoramento; também estabelece adequação dos sistemas de avaliação em larga escala à reforma, viabilizando a regulação dos processos formativos, atingindo a autonomia intelectual dos docentes e a liberdade democrática das comunidades escolares.

Assim, dando amparo à Reforma do Ensino Médio, a BNCC e as Novas Diretrizes Curriculares Nacionais para o Ensino Médio apresentam um viés eficientista, na medida em que se opõem ao currículo disciplinar e alinham-se à noção de educação voltada para a formação de competências, com base em aprendizagens imediatamente interessadas, supostamente necessárias ao enfrentamento dos desafios da sociedade contemporânea.

Esse discurso é retomado visando adequar a escola a supostas mudanças do mundo do trabalho, associadas de modo mecânico e imediato às inovações de caráter tecnológico e organizacional, propiciando uma "formação administrada", controlada e instrumental (Silva, 2018, p. 11).

Silva (2018) destaca que esse controle ocorre, principalmente por meio das estratégias de avaliação, que enfatizam apenas o produto, ignorando o processo educacional e suas determinações em cada contexto.

De acordo com a autora,

A noção de competências, incorporada como um dispositivo capaz de produzir mudanças na organização curricular do ensino médio com vistas a superar os limites da excessiva disciplinarização e baseado no acúmulo de informações, mostra-se limitada por seu caráter pragmático e a-histórico. Ela reproduz em outras bases os limites postos pelo currículo disciplinar e sequencial, pois não realiza a inversão necessária, ou seja, não permite o aprendizado e o exercício da reflexão com a profundidade que a formação cultural exige (Silva, 2018, p. 12).

A ligação estabelecida entre formação por competências, formação para o mundo do trabalho e o exercício da cidadania busca adequar a formação da subjetividade da classe trabalhadora ao atual estágio de desenvolvimento das forças produtivas, que assume um caráter regressivo e instrumental, aprofundando a precarização das condições de vida e trabalho das camadas populares em nome da reprodução da acumulação capitalista. 
Tanto a Base Nacional Comum Curricular, quanto as Diretrizes Curriculares Nacionais para o Ensino Médio aprovadas em 2018 representam um retrocesso em relação às políticas educacionais desenvolvidas em âmbito normativo após 2003, aproximando-se e até acentuando as perspectivas implementadas na década de 1990. Sintetizam portanto um processo de restauração da hegemonia neoliberal, relacionado, principalmente às forças empresariais, que pretendem, sob o discurso de modernização e adequação da etapa final da educação básica, impor seus interesses no âmbito formativo e produtivo, fragilizados, mesmo que de forma sutil, pelas perspectivas assumidas na década de 2000.

\section{Considerações finais}

A recente reforma do Ensino Médio, desencadeada em um momento de turbulência política e econômica, apresenta um caráter autoritário e regressivo, impondo uma perspectiva de formação cujo objetivo é legitimar a hegemonia neoliberal no processo de disputa entre classes e frações de classes, em torno do projeto formativo e curricular do Ensino Médio.

Destaca-se o protagonismo dos setores empresariais no processo de elaboração da políticas educacionais em curso, adequando o projeto formativo do Ensino Médio aos interesses produtivos, tanto no que se refere à formação da subjetividade e para o trabalho, quanto às possibilidades de aproximar as políticas educacionais de mecanismos de produção de mais valia, ou seja, transformar os serviços em mercadoria.

O esforço de análise dos documentos que compõem o arcabouço normativo da Reforma permite evidenciar um movimento de privatização e de subsunção do Ensino Médio à lógica mercantil. A partir do retorno à centralidade curricular com base em competências, a reforma intensifica o caráter utilitarista da educação, fundamentando o processo formativo em habilidades e atitudes que atendam as necessidades imediatas do mercado de trabalho, ao mesmo tempo em que desloca o núcleo pedagógico da formação geral (reduzida tanto no sentido temporal quanto no acadêmico) para uma educação especializada, ao enfatizar a opção por itinerários formativos limitados a determinadas áreas do conhecimento ou à formação técnica e profissional.

O Novo Ensino Médio representa um projeto de formação estruturado pelo esvaziamento dos conhecimentos e pelo empobrecimento das práticas formativas, pautado em um processo de prescrição de padrões curriculares. A proposta volta-se para a preparação dos jovens para o trabalho ou para a precariedade e flexibilidade de um futuro sem trabalho, solapando a possibilidade de formação com base científica, técnica e tecnológica e o direito à cidadania efetiva (Frigotto, 2018).

Desse modo, constata-se que as atuais estratégias educacionais estão submissas aos processos de reestruturação do capital com a retomada radical do neoliberalismo, reforçando o caráter de contrarreforma e de conservadorismo das medidas tomadas e suas aproximações, guardadas as singularidades históricas, com o movimento ocorrido nos anos de 1990. Retoma, portanto, um velho projeto formativo, acentuando o caráter dualista da formação proposta para o Ensino Médio.

Tal processo não se dá em um contexto passivo, ou neutro. As contradições entre capital e trabalho acendem disputas em torno da configuração de projetos educacionais que atendam as expectativas dos trabalhadores. Embora histórica e hegemonicamente comprometidas com os interesses burgueses, as políticas educacionais para o Ensino Médio têm sido constantemente tensionadas pela participação organizada da classe trabalhadora, na luta pela construção de um projeto formativo de caráter humanista e progressista. 


\section{Referências}

Azevedo, J. M. L. (2004). A Educação como Política Pública. 3. ed. Campinas: Autores Associados.

Civatta, M. \& Ramos, M. (2012). A "era das diretrizes": a disputa pelo projeto de educação dos mais pobres. Revista Brasileira de Educação [online]. 17(49), 11-37. DOI: https://dx.doi.org/10.1590/S141324782012000100002.

Constituição da República Federativa do Brasil. São Paulo: Imprensa Oficial do Estado de São Paulo, 1988.

Costa e Silva, F. P. (2019). A reforma do Ensino Médio no governo Michel Temer (2016 - 2018). Dissertação (Mestrado em Educação: Conhecimento e Inclusão Social), Universidade Federal de Minas Gerais, Belo Horizonte.: https://repositorio.ufmg.br/handle/1843/32634.

Decreto no 5.154 de 23 de julbo de 2004. (23 de julho de 2004). Regulamenta o \2o do art. 36 e os arts. 39 a 41 da Lei no 9.394, de 20 de dezembro de 1996, que estabelece as diretrizes e bases da educação nacional, e dá outras providências. Brasília.

Delors, J. (1998). Educação: um tesouro a descobrir. São Paulo: Cortez.

Emenda Constitucional no 59 de 11 de novembro de 2009. (11 de novembro de 2009). Diário Oficial da União, Brasília.

Freitas, L. C. (2018). A reforma empresarial da educação: nova direita, velhas ideias. São Paulo: Expressão Popular.

Frigotto, G. (2018). A produção do conhecimento em educação num contexto de estado de exceção e interdição dos direitos. Holos, 5, 245-258. DOI: https://doi.org/10.15628/holos.2018.6977.

Gonçalves, S. R. V. (2017). Interesses mercadológicos e o "novo" ensino médio. Revista Retratos da Escola, Brasília, v. 11(20), 131-145, jan./jun. DOI: https://doi.org/10.22420/rde.v11i20.753.

Gramsci, A. (2002). Caderno 5. In: Cadernos do cárcere. v 5. Rio de Janeiro: Civilização Brasileira.

Harvey, D. (2016). Condição Pós-Moderna. São Paulo: Loyola.

Kuenzer, A. Z. (2007). Da dualidade assumida à dualidade negada: o discurso da flexibilização justifica a inclusão excludente. Educaşão e Sociedade, Campinas, vol. 28, n. 100, p. 1153-1178, out. DOI: https://doi.org/10.1590/S0101-73302007000300024.

Lei no 13.005/2014, de 25 de junho de 2014. (25 de julho de 2014). Aprova o Plano Nacional de Educação e dá outras previdências. Câmara dos Deputados. Brasília.

Lei $n^{\circ} 13.415$, de 16 de fevereiro de 2017. (16 de fevereiro de 2017). Altera as Leis $n^{\circ}$ 9.394, de 20 de dezembro de 1996, que estabelece as diretrizes e bases da educação nacional, e 11.494, de 20 de junho 2007, que regulamenta o Fundo de Manutenção e Desenvolvimento da Educação Básica e de Valorização dos Profissionais da Educação [...] . Diário Oficial da União. Brasília. 
Lei n 9.394, de 20 de dezembro de 1996.(20 de dezembro de 1996). Estabelece as diretrizes e bases da educação nacional. Diário Oficial da União. Brasília.

Libâneo, J. C.; Oliveira, J. F.; Toschi, M. S. (2012). Educaşão escolar: políticas, estrutura e organização. 10. ed. São Paulo: Cortez.

Lopes. C. A. (2019). Itinerários formativos na BNCC do Ensino Médio: identificações docentes e projetos de vida juvenis. Revista Retratos da Escola, 13(25), 59-75. DOI: https://doi.org/10.22420/rde.v13i25.963.

Manacorda, M. A. (1991). Marx e a pedagogia moderna. São Paulo: Cortez: Autores Associados.

Manfredi, S. M. (2002). Educação Profissional no Brasil. São Paulo: Cortez.

Medida Provisória $n^{\circ}$ 746, de 22 de setembro de 2016. (22 de setembro de 2016).Diário Oficial da União. Brasília.

Morello, A. C. \& Horn, G. B. (2020). A reforma curricular do Ensino Médio e a Base Nacional Comum Curricular. O Sisifo. 3 (2). Jornal do NESEF. Curitiba. Recuperado em: http://www.educacao.ufpr.br.

Neves, L. M. W. (2005). A nova pedagogia da hegemonia: estratégias do capital para educar o consenso. São Paulo: Xamã.

Neves, L. M. W.(2011). A nova pedagogia da hegemonia no Brasil (Entrevista). Perspectiva, Florianópolis, v. 29, n. 1, 229-242, jan./jun. DOI: 10.5007/2175-795X.2011v29n1p229.

Oliveira, D. A. (2015). Nova gestão pública e governos democrático-populares: contradições entre a busca da eficiência e a ampliação do direito à educação. Educação \& Sociedade, Campinas, 36(132), 625646, jul.-set. doi: DOI: http://dx.doi.org/10.1590/ES0101-73302015152440.

Oliveira, E. (2006). Toyotismo no Brasil: desencantamento da fábrica, envolvimento e resistência. São Paulo: Expressão Popular.

Parâmetros Curriculares Nacionais: ensino médio. (2000). Mistério da Educação. Secretaria de Educação Básica. Brasília.

Parecer no 15, de 1 de junho de 1998. (1 de julho de 1998). Conselho Nacional de Educação. Câmara da Educação Básica. Institui as Diretrizes Curriculares Nacionais para o Ensino Médio. Brasília.

Projeto de Lei ñ 6.840 , de 2013. (2013). IL. Câmara dos Deputados. Altera a Lei no 9.394, de 20 de dezembro de 1996, que estabelece as diretrizes e bases da educação nacional, para instituir a jornada em tempo integral no ensino médio, dispor sobre a organização dos currículos do ensino médio em áreas do conhecimento e dá outras providências. Brasília.

Resolução CNE/CEB ñ 3, de 21 de novembro de 2018. (21 de novembro de 2018). Atualiza as Diretrizes Curriculares Nacionais para o Ensino Médio. Conselho Nacional de Educação. Câmara da Educação Básica. Brasília.

Resolução no 2, de 30 de janeiro de 2012. (30 de janeiro de 2012a). Institui as Diretrizes Curriculares Nacionais para o Ensino Médio. Conselho Nacional de Educação. Câmara da Educação Básica. Brasília. 
Resolução nº 4, de 17 de dezembro de 2018. (17 de dezembro de 2018). Institui a Base Nacional Comum Curricular na Etapa do Ensino Médio. Diário Oficial da União. Brasília.

Resolução ñ 4, de 8 de dezembro de 1999. (BRASIL, 1999). Institui as Diretrizes Curriculares Nacionais para a Educação Profissional de Nível Técnico. Brasília.

Resolução $n^{\circ}$ 6, de 20 de setembro de 2012. (20 de setembro de 2012b). Define Diretrizes Curriculares Nacionais para a Educação Profissional Técnica de Nivel Médio. Conselho Nacional de Educação. Câmara da Educação Básica. Brasília.

Silva, M. R. \& Scheibe, L. (2017). Reforma do ensino médio: pragmatismo e lógica mercantil. Revista Retratos da Escola, 11(20), 19-31, jan./jun. doi: DOI: https://doi.org/10.22420/rde.v11i20.769.

Silva, M. R. (2018). A BNCC da Reforma do Ensino Médio: o resgate de um empoeirado discurso. Educação em Revista. 34(e214130), 1-15. DOI: https://doi.org/10.1590/0102-4698214130.

Silva, M. R.. \& Abreu, C. B, M. (2008). Reformas pra quê? As políticas educacionais nos anos de 1990, o "novo projeto de formação" e os resultados das avaliações nacionais. Perspectiva: Florianópolis, v. 26(2), jul./dez. DOI: https://doi.org/10.5007/2175-795x.2008v26n2p523.

Zanatta, S. C. (2017). A implantação de uma Base Nacional Comum Curricular - BNCC no contexto do progresso ensino e aprendizagem de Física. In: Neves, M. C. D.; Zanatta, S. C.; Trogello, A. G. (Orgs.). Conbecimento público, educação tutorial e outras reflexões sobre o ensino de Ciências. Maringá: LCV-UEM. p. 311330.

\section{Sobre a Autora}

\section{FERNANDA RIBEIRO DE SOUZA}

(iD) ORCID: https://orcid.org/0000-0002-2984-2565

Doutoranda no Programa de Pós-graduação em Sociedade, Cultura e Fronteiras, da Universidade Estadual do Oeste do Paraná. Mestre em Educação pela Universidade Estadual do Oeste do Paraná. Graduada em Pedagogia pela Universidade Estadual do Oeste do Paraná e em Licenciatura em Ciências Biológicas pela Universidade Federal de Santa Catarina. Atua como Pedagoga no Instituto Federal do Paraná.

E-mail: ffernandaa6@gmail.com

Enviado: 06 out. 2020.

Aprovado: 04 mar. 2021. 